Resenhas 



\section{Capitalismo \& escravidão e a historiografia sobre a escravidão nas Américas}

Rafael de Bivar Marquese

O VASTO campo de estudos sobre a escravidão negra nas Américas, o livro Capitalismo é escravidão é um de seus mais notáveis resultados. Quando a primeira edição em inglês veio a lume, em 1944, Eric Williams era um jovem historiador com 33 anos de idade. $\mathrm{Na}$ ocasião, ele vivia nos Estados Unidos, lecionando ciências sociais e política em Howard. Essa universidade fora fundada na capital federal logo após o término da Guerra Civil norte-americana, concebida para a educação dos afrodescendentes recém-saídos da escravidão e com corpo docente majoritariamente formado por professores negros. Williams nela ingressou em 1939, um ano após obter seu doutorado pela Universidade de Oxford, com uma tese intitulada The Economic Aspect of the Abolition of West Indian Slave Trade and Slavery. ${ }^{1}$

Das origens da tese à publicação do livro, o caminho foi difícil. Williams nasceu na colônia britânica de Trinidad \& Tobago. Primogênito de onze irmãos, filho de um modesto funcionário dos correios locais, sua infância foi marcada por grandes privações, o que não o impediu de destacar-se como ótimo estudante na escola primária. Aos onze anos, obteve uma bolsa para estudar no Queen's Royal College, em Porto de Espanha, um dos raros canais de ascensão social via educação abertos à população negra pobre da colônia. Nessa instituição, o historiador, jornalista e militante político C. L. R. James foi um de seus tutores. Dez anos mais velho, ele seria

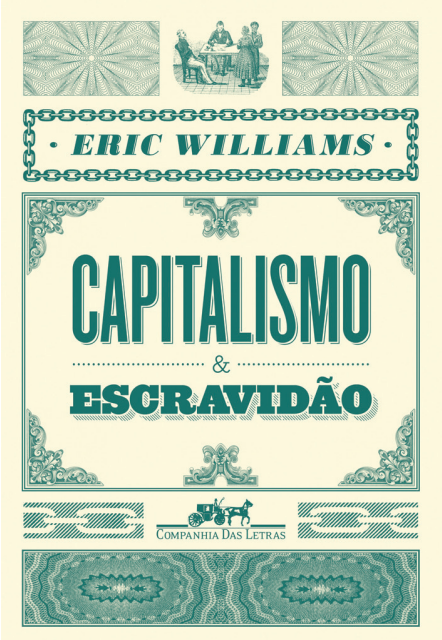

\section{WILLIAMS, E. Capitalismo e escravidão.}

Trad. Denise Bottmann. São Paulo:

Companhia das Letras, 2012.

uma referência decisiva em toda sua vida intelectual e política. Com excelente desempenho acadêmico, Williams ganhou, em 1931, uma das três vagas anualmente alocadas para todo o Caribe britânico das disputadíssimas Island Scholarships, que franqueavam aos laureados a possibilidade de estudar no sistema "Oxbridge".

A influência de James deve ter pesado na escolha de Williams pelo curso de história, contra a predileção de seu pai, que preferia vê-lo estudar direito ou medicina. De todo modo, James e Williams mudaram-se no mesmo ano, em 1932, para a Inglaterra. Tendo por ganha-pão o jornalismo esportivo (cricket era sua especialidade), James mergulhou rapida- 
mente nos círculos anticoloniais radicais de Londres, que envolveram em diferentes situações militantes vindos tanto das Índias Ocidentais como da África - dentre os quais se destacaram George Padmore, Kwame Nkrumah e Jomo Kenyatta. Mesmo que apartado da militância de tempo integral, Williams não deixou de travar contatos próximos com esses intelectuais e políticos negros oriundos do mundo colonial. Tais afinidades the serviram como um claro contrapeso ao que encontrara em Oxford, onde o domínio da chamada "escola imperial" era absoluto.

A perspectiva de análise do passado colonial britânico veiculada por essa escola, ainda que não fosse unívoca, esposava os fundamentos ideológicos que, desde a segunda metade do século XIX, vinham legitimando o império. Seu principal nome em Oxford, nos anos em que Williams lá esteve, foi Reginald Coupland. No período entre guerras, Coupland exerceu completo controle sobre os temas relativos à história do império naquela instituição, não raro valendo-se de seu posto como catedrático para recrutar estudantes para a administração imperial, da qual ele próprio participou em momentos decisivos. ${ }^{2}$ Em todos seus trabalhos acadêmicos e políticos, Coupland enfatizava a capacidade moral do império britânico em moldar um "mundo melhor" e ajudar os povos "atrasados" a avançar em direção à liberdade. No longo prazo, o império se justificaria pelo seu próprio resultado final, isto é, pela formação nações iguais livremente associadas à Commonwealth britânica, como o comprovavam o Canadá e a Austrália. Mais importante para os presentes fins é o fato de que, em 1933, ano do centenário do ato de emancipação nas co- lônias inglesas e da morte de William Wilberforce, Coupland publicou o livro The British Anti-Slavery Movement, no qual ressaltava o papel crucial das ideias humanitárias morais e religiosas da passagem do século XVIII para o XIX, descarnadas de interesses materiais imediatos, na conformação do movimento que levou à abolição da escravidão negra caribenha. $^{3}$

A pesquisa que Williams desenvolveu ao longo de seu doutorado, ao focar os fatores econômicos na abolição do tráfico transatlântico de escravos e da escravidão negra no império britânico, afastou-se dos cânones de interpretação então vigentes sobre aquele processo. Tratava-se de um trabalho que seguia à risca o padrão consagrado de uma tese acadêmica em história, sobretudo no que se refere ao encadeamento cronológico da narrativa e ao domínio exaustivo que demonstrava sobre a documentação. Dividida em doze capítulos, a tese de doutorado concentrou-se no período de 1783 a 1838, examinando o declínio da importância econômica das Índias Ocidentais para o império britânico após a Revolução Americana; o crescimento do tráfico negreiro e da escravidão em Saint-Domingue; as tentativas de conquista britânica da colônia francesa durante o curso da revolução escrava; o impacto do fracasso dessa tentativa para a abolição do tráfico transatlântico em 1807; a decadência da produção açucareira do Caribe britânico em face dos demais competidores mundiais; as ameaças das rebeliões escravas de Barbados, Demerara e Jamaica e seus impactos sobre a opinião pública britânica; os limites colocados pelo monopólio das Índias Ocidentais para o avanço das forças capitalistas na metrópole. Uma referên- 
cia básica para Williams compreender o declínio econômico das Índias Ocidentais foi o livro de Lowell Joseph Ragatz (The Fall of the Planter Class in the British Caribbean, de 1928), referência essa que seria mantida no livro publicado seis anos depois após a defesa da tese. ${ }^{4}$

O malogro em publicá-la rapidamente e, também, em encontrar um emprego no sistema universitário britânico levou Williams a se mudar para os Estados Unidos. Em Howard, encontrou condições intelectuais excelentes, que muito o estimularam a rever o plano original de seu trabalho. ${ }^{5} \mathrm{O}$ elemento mais importante para a reconfiguração do projeto foi o aparecimento, no mesmo ano de defesa da tese, da monumental obra de C. L. R. James sobre a Revolução de Saint-Domingue. ${ }^{6}$ Como Williams deixou claro nos comentários bibliográficos, sua interpretação sobre as relações contraditórias entre capitalismo e escravidão foi diretamente retirada de $O s j a-$ cobinos negros. Williams adicionaria, ao livro de 1944, três eixos ausentes de sua tese de doutorado de 1938, que se concentrara no papel das forças econômicas do capitalismo industrial para a destruição da escravidão no Império britânico: primeiro, a compreensão da escravidão negra como um fenômeno econômico, em uma elaboração da ideia do racismo funcional colocado a serviço da exploração de classe; segundo, a centralidade do complexo escravista atlântico para a formação do capitalismo industrial na Inglaterra; terceiro, o papel da resistência escrava para a derrubada da escravidão - um tema já desenhado, contudo pouco desenvolvido, no doutorado. Mas, não só: Williams inspirou-se igualmente no tom político e no estilo de C. L. R. James, em sua escrita direta, ácida e en- volvente, que expressava a concepção de que a prática do ofício do historiador era uma atividade eminentemente política. Não por acaso, a finalização de Capitalismo es escravidão foi intermediada pela publicação do primeiro livro de Willia$\mathrm{ms}$, The negro in the Caribbean, de 1942, fruto de uma viagem ao Caribe (Cuba, Porto Rico, República Dominicana e Haiti foram os países visitados) na qual travou contato com vários intelectuais de peso da região, dentre os quais Fernando Ortiz, e em que pôde constatar os efeitos similares, porém desiguais, da herança da economia açucareira escravista colonial para os povos negros antilhanos.

A plataforma política inscrita em $\mathrm{Ca}$ pitalismo \& escravidão era distinta de Os jacobinos negros: James pensava na revolução mundial e, em especial, nas potencialidades do Pan-Africanismo; Williams, na afirmação do nacionalismo caribenho. Ivar Oxaal esclarece que essa distinção estaria na base do rompimento político dos dois na década de 1960 , mas, no contexto dos anos 1930-1940, o que sobressaía era a convergência. Nas suas palavras,

ambos os estudos ressaltavam o papel decisivo do conflito de classes na história. Williams atacou a complacência moral associada ao entendimento britânico de seu passado escravista; James procurou demolir a mentira histórica da passividade negra sob a escravidão. Ambos eram trabalhos radicais de investigação escritos da perspectiva de intelectuais negros marginalizados, cujas experiências os tornaram conscientes da hipocrisia que subjazia à auto-congratulação piedosa da metrópole a respeito das relações com suas colônias. ${ }^{7}$ 


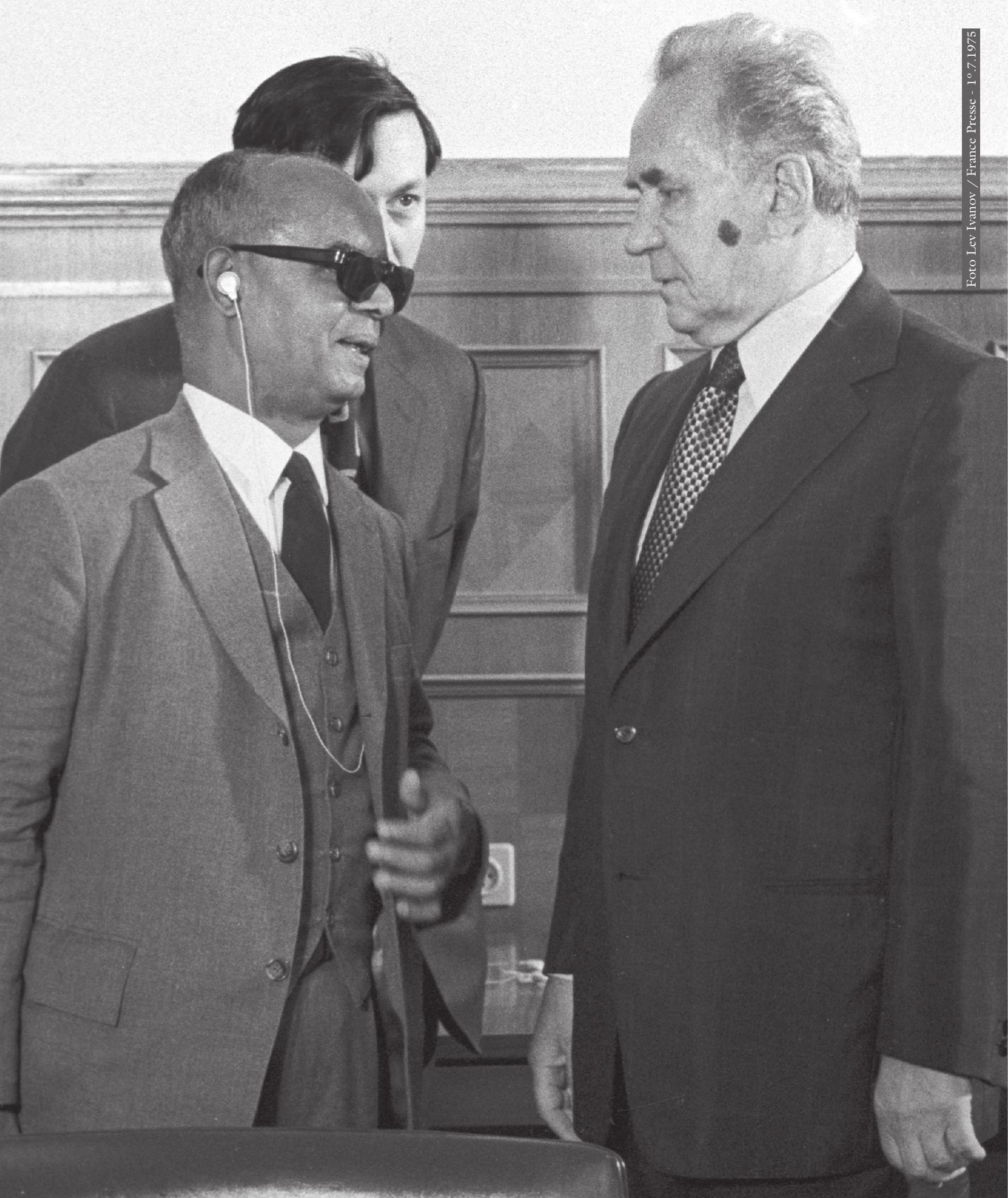

Eric Williams e Alexei Kosygin. 
De fato, Capitalismo \& escravidão batia de frente com o establishment de Oxford e, por extensão, com toda a ideologia imperial britânica. O estilo irônico e a organização esquemática, não necessariamente cronológica dos capítulos do livro demonstravam que Williams abandonara os padrões de uma tese acadêmica em busca em uma forma que atingisse diretamente os leitores caribenhos, auxiliando-os a fundar politicamente o nacionalismo. Atacar a interpretação humanitarista da abolição consagrada pelos atores do século XIX, reatualizada por Coupland em 1933, significava atacar as justificativas ideológicas do imperialismo britânico na conjuntura crítica da Segunda Guerra Mundial. O novo emprego que assumiu nessa época indicava o caminho que Williams pretendia seguir. Em 1943, ele passou a acumular com o trabalho em Howard um cargo na Anglo-American Caribbean Commission, o que em poucos anos o afastaria definitivamente da vida acadêmica. Williams romperia com a comissão em 1955, mergulhando de cabeça no movimento pela emancipação de Trinidad \& Tobago, do qual seria o grande líder, por meio da direção do People's National Movement. De 1956 a 1981, ano em que faleceu, Williams foi sucessivamente ministro-chefe de Trinidad \& Tobago (1956-1959), premiê do país na Federação das Índias Ocidentais (1959-1962) e primeiro-ministro do país independente (de 1962 em diante), cargos ocupados sempre por meio de eleições democráticas.

Salvo algumas exceções, todas da lavra de pesquisadores negros norte-americanos ou caribenhos, o acento político de Capitalismo \& escravidão foi rejeitado pelos historiadores profissionais do mundo anglo-saxônico, o que pode ser aquilatado pelas resenhas negativas publicadas sobre o livro na segunda metade dos anos 1940. Uma delas chama a atenção. Em 1946, Frank Tannenbaum escreveu um duro comentário, no qual deixava de lado o cerne da dupla tese de Williams sobre as relações entre capitalismo e escravidão ${ }^{8}$ para criticar sua explicação a respeito da gênese do racismo nas Américas - segundo Tannenbaum, vincada por uma ênfase desmedida nos fatores econômicos. Salta aos olhos as inscrições políticas dessa resenha, com uma posição antimarxista abertamente contrária ao nacionalismo caribenho então em curso. ${ }^{9}$ A recepção hostil certamente foi responsável pelo fato de o livro ter vendido pouco após um início relativamente promissor, quando $\mathbf{1 . 5 0 0}$ cópias chegaram a ser reimpressas em menos de um ano. Sua trajetória se alteraria apenas nos anos 1960, quando, em contexto marcado pela independência na África, pela revolução na América Latina e, em especial, pelo movimento dos direitos civis nos Estados Unidos, saíram novas edições, com tiragens enormes, e ele foi finalmente publicado na Inglaterra. $^{10}$

Um momento em que, por razões semelhantes, o livro adquiriu ótima fortuna na historiografia brasileira. A primeira edição em inglês de Capitalismo é escravidão foi contemporânea ao aparecimento de uma obra canônica para a compreensão do passado brasileiro. Com efeito, apenas dois anos antes da publicação do livro de Eric Williams, veio a lume Formação do Brasil contemporáneo, de Caio Prado Jr. Não obstante suas diferenças, ambos os livros apresentavam vários pontos em comum: a importância conferida às economias das regiões tro- 
picais do Novo Mundo para a formação do capitalismo europeu, o peso decisivo da escravidão negra nelas, os impactos negativos da herança colonial escravista para as formações nacionais no Caribe e na América Latina. ${ }^{11}$ As convergências entre as perspectivas de Williams e Prado Jr. podem ser aquilatadas pelo trabalho pioneiro de Alice Piffer Canabrava sobre a indústria açucareira antilhana na primeira metade do século XVIII: finalizado em 1945, sem tempo hábil, portanto, para tomar ciência de Capitalismo \& escravidão, a tese de Canabrava se aproximava notavelmente das conclusões a que havia chegado Eric Williams, valendo-se para tanto do modelo analítico de Caio Prado Jr. e da prática de uma história econômica associada à primeira geração da Escola dos Annales. ${ }^{12}$

Não é surpreendente, assim, a recepção positiva que a obra de Williams encontrou nas ciências sociais brasileiras a partir de fins da década de 1950, impacto que se prolongou por duas décadas. Capitalismo \& escravidão foi relevante tanto para Celso Furtado, economista filiado ao pensamento da Cepal, como para o grupo de sociólogos da Universidade de São Paulo associados a Florestan Fernandes e Roger Bastide, que dele se utilizaram para reavaliar e criticar teses consagradas sobre a democracia racial brasileira. ${ }^{13} \mathrm{~A}$ perspectiva analítica de Williams, enfim, casava-se bem com uma tradição que vinha ganhando corpo no Brasil e na América Latina em geral, e que logo desembocaria na teoria da dependência. ${ }^{14} \mathrm{O}$ melhor exemplo disso está na tese de doutorado de Fernando Henrique Cardoso, ex-aluno de Fernandes: seu enquadramento para compreender o problema da transição da escravidão para o capitalismo na eco- nomia pecuarista do Rio Grande do Sul, um dos pontos de partida de suas posteriores investidas sobre o problema da dependência na América Latina, escorou-se inteiramente nos pressupostos do livro de Eric Williams. ${ }^{15}$

Os trabalhos que mais se valeram do esquema interpretativo de Eric Williams, no entanto, foram elaborados por historiadores igualmente vinculados à USP. Dois deles tornaram-se matriciais para a historiografia brasileira, obrigatórios em seus respectivos domínios. O primeiro foi a tese de livre-docência de Emília Viotti da Costa, de 1964, que tratou da crise da ordem escravista nas regiões cafeeiras do centro-sul do Brasil; o segundo foi a tese de doutorado de Fernando Novais, de 1973, que examinou a crise do colonialismo português na América na virada do século XVIII para o XIX. ${ }^{16}$ Essas obras de historiadores e cientistas sociais da USP converteram-se, na virada da década de 1960 para a de 1970, nas referências básicas para os pesquisadores que lidaram com o passado escravista brasileira, seja no período colonial, seja no período imperial. O impacto internacional não foi menos relevante: David Brion Davis e Eugene Genovese, por exemplo, muito se valeram das obras desses historiadores e cientistas sociais brasileiros para compreender de forma comparada o problema das diferenças e das aproximações entre os sistemas escravistas americanos. ${ }^{17}$

Mesmo os historiadores que procuraram, nos anos 1970, dar consistência teórica ao conceito de modo de produção escravista colonial, portanto sendo críticos do modelo de Eric Williams, não deixaram de reconhecer no seu trabalho - e nos que, a exemplo de Emília Viotti da Costa e Fernando Novais, 
seguiram-no de perto - as marcas da referência fundadora. Tais foram os casos de Ciro Flamarion Santana Cardoso e Jacob Gorender. Ao elaborarem o conceito, ambos estavam engajados no problema do debate sobre a formação do capitalismo no Brasil e na América Latina - em nosso país, parte do acerto de contas com a derrota que a esquerda sofrera em $1964 .{ }^{18}$ Aliás, foi no contexto dos debates travados dentro da esquerda brasileira sobre os modos de produção na América Latina que apareceu a primeira edição em português de Capitalismo é escravidão. Ela foi inserida, em 1975, com tradução de Carlos Nayfeld, na coleção América: economia \& sociedade, coordenada por Ilmar Rohloff de Mattos e Ari Araújo Viana para a editora Pallas. Também fizeram parte dessa coleção a coletânea de ensaios sobre modos de produção editada por Théo Santiago e a Economia política da escravidão, de Eugene Genovese, originalmente publicada em inglês em 1965. ${ }^{19}$

Em que pese toda a crítica a Eric Williams, Caio Prado Jr. e, por extensão, à teoria da dependência, Ciro Cardoso e Jacob Gorender nunca negaram a relevância das abordagens estruturais para a análise dos processos sociais escravistas. O conceito de modo de produção escravista colonial, ao considerar o fato colonial como uma dimensão estrutural, reconhecia explicitamente o legado positivo das teses elaboradas a partir daqueles autores. Mas, pode-se afirmar que foi com Ciro Cardoso, no final dos anos 1970, que começou um dos dois deslocamentos (o outro foi o da nova história social da escravidão) que em pouco tempo contribuiriam para sepultar o aporte que as perspectivas de Williams, Prado Jr. e outros haviam trazido para a histo- riografia brasileira e, com elas, a validade da categoria capitalismo para conferir inteligibilidade à compreensão do nosso passado escravista.

O contexto casado da redemocratização política e da crise econômica na década de 1980 abriu caminho para a percepção, entre os historiadores da escravidão brasileira, de que a agenda das duas décadas anteriores era coisa do passado. Os debates sobre o modo de produção escravista colonial se esgotaram, o ofício da história se profissionalizou no Brasil, com a consolidação do sistema da pós-graduação, e houve um movimento de redescoberta dos arquivos. Ademais, foi nos anos 1980 que se consolidaram as principais vertentes de estudo da escravidão brasileira que até hoje ditam a agenda de pesquisa sobre o assunto. ${ }^{20}$

Quando todos esses processos ocorriam, alguns historiadores de peso da geração imediatamente anterior, que fundaram a nova agenda e estavam formando os novos pesquisadores, atacaram explicitamente a validade a herança de Williams et al., desautorizando-a de forma definitiva. Ciro Cardoso foi um dos nomes centrais desse impulso. Tendo realizado sua tese de doutorado sobre a escravidão na Guiana Francesa, ele foi um dos poucos historiadores brasileiros dos anos 1970-1980 - senão o único - que praticou a sério a história comparada da escravidão negra nas Américas, com vasto conhecimento acerca da bibliografia sobre o Caribe. Em diversos textos dos anos 1980, afirmou com todas as letras que Capitalismo \& escravidão era coisa do passado, um trabalho superado e irrecuperável. ${ }^{21}$ Vale citar as palavras de um texto de balanço crítico que ele inseriu em um volume que reunia alguns dos principais nomes da nova geração de 
pesquisadores da escravidão brasileira, publicado por ocasião das comemorações do centenário da abolição no Brasil: a concepção de Eric Williams sobre as relações entre capitalismo e escravidão,

hegemônica e não contestada por muito tempo, serviu de origem e foi um dos esteios centrais, em nosso país, tanto no caso da "escola sociológica de São Paulo” quanto, posteriormente, no dos escritos que desenvolveram a noção de Antigo Sistema Colonial. Hoje o Brasil talvez seja o seu último reduto: já muito desacreditada por sucessivos golpes assestados nos últimos vinte anos por muitas pesquisas, a teoria de Eric Williams, até 1987 pelo menos, continuava a ser afirmada - às vezes "por tabela", de segunda ou terceira mão - em alguns trabalhos brasileiros sobre escravidão e abolição. ${ }^{22}$

Ciro Cardoso se referia aos "golpes assestados" por historiadores norte-americanos e ingleses, desde fins dos anos 1960, ao esquema interpretativo de Williams. Os questionamentos incidiram tanto sobre as explicações concernentes ao peso do complexo escravista colonial para a acumulação capitalista na Inglaterra como sobre a importância dada dos fatores econômicos no processo de abolição do tráfico negreiro e da escravidão. Em relação ao primeiro ponto, as revisões enfatizaram as chamadas "causas internas" da Revolução Industrial: variáveis endógenas ao mundo metropolitano inglês, como crescimento populacional, progresso agrícola, abundância de recursos minerais e inovações técnicas locais teriam sido muito mais relevantes, para a decolagem industrial na virada do século XVIII para o XIX, do que o avanço anterior do comércio ultramarino. O ataque, aqui, não era apenas contra Williams, mas contra toda uma perspectiva - da qual ele foi um dos fundadores - que destacava o peso decisivo do colonialismo para o descolamento do Ocidente europeu em relação ao restante do globo. Como parte da crítica ao primeiro ponto, houve também os trabalhos que estimaram a lucratividade do tráfico negreiro, apontando que ela não representava nada de excepcional dentro do conjunto de investimentos disponíveis para os agentes econômicos do século XVIII. Em relação ao segundo ponto, partindo de estimativas sobre a lucratividade das plantations escravistas e sobre o crescimento da produção escravista britânica na conjuntura da abolição do tráfico transatlântico de escravos, os historiadores críticos de Williams sugeriram que, em 1807, os interesses econômicos ligados à industrialização britânica não tinham razões imediatas para atacar o complexo escravista das Índias Ocidentais; a partir de tal constatação, as explicações que forneceram se voltaram ou para o humanitarismo como o motor básico do antiescravismo, ou para o impulso democrático da Era das Revoluções como o elemento que galvanizou a opinião pública britânica contra a escravidão. $^{23}$

Para Ciro Cardoso, tais trabalhos trouxeram a superação definitiva de Williams, sepultando por completo a perspectiva teórica que ele avançara. ${ }^{24}$ Mas, havia um problema grave em sua avaliação. Em 1984, vários historiadores de renome se reuniram em uma conferência em Bellagio - transformada em livro em 1987 - para discutir seriamente a herança do trabalho de Eric Williams. Em 1985, iniciou-se, nas páginas da American Historical Review, 
o debate entre Thomas Haskell, David Brion Davis e John Ashworth sobre as relações entre antiescravismo e capitalismo industrial, modulado conforme os termos estabelecidos por Williams. Em 1988, foi publicado o monumental livro de Robin Blackburn sobre a queda da escravidão colonial, que reatualizava, de forma bastante sofisticada, as teses de James e Williams. Finalmente, em 1990, Ronald Findlay publicou um importante trabalho no qual elaborava um modelo econométrico sobre o comércio triangular que dava suporte à interpretação de Williams a respeito do peso das colônias escravistas caribenhas para o crescimento econômico inglês. ${ }^{25}$ Em resumo: em 1988, o Brasil estava longe de ser o "último reduto" de Williams.

As palavras de Ciro Cardoso, no entanto, casaram-se bem com uma tendência que vinha ganhando força na historiografia brasileira naquela época, e que logo se tornou comum. Refiro-me ao abandono das perspectivas estruturais que procuravam inserir o passado do Brasil no processo de formação do capitalismo mundial. A própria categoria capitalismo, tomada como um constructo anistórico e abstrato, incapaz de conferir inteligibilidade às experiências vividas pelos sujeitos históricos concretos, desapareceu do horizonte analítico. ${ }^{26}$ A despeito dos méritos dessa historiografia, cuja contribuição para o melhor entendimento da história da escravidão no Brasil é considerável, ela acabou por conduzir a um descaso com os processos históricos de longa duração e os quadros globais mais amplos nos quais se inscreveu o sistema escravista brasileiro.

Nisso reside uma das mais originais contribuições de Eric Williams e C. L. R. James: com base na leitura de Marx, eles estiveram dentre os primeiros historiadores a conectar a formação do capitalismo europeu à escravização em massa dos africanos no Novo Mundo. A escravidão negra, assim, foi alçada ao coração da gênese do mundo moderno. Ao mesmo tempo, eles também foram os primeiros a apresentar um modelo de análise que encarava os processos históricos desenrolados no espaço atlântico como uma unidade orgânica, ao apontar como eventos no Velho Mundo (Europa e África) e no Novo Mundo foram mutuamente determinantes. Nesse sentido, ambos foram pioneiros no que, em tempos recentes, vêm sendo denominado como "História Atlântica", isto é, uma perspectiva que procura tratar de forma integrada os fluxos de pessoas, mercadorias e idéias que conectaram, do século $\mathrm{XV}$ ao XIX, as três margens do oceano Atlântico.

Não por acaso, diversos livros publicados na última década indicam como a obra de Eric Williams pode estimular boas releituras, capazes de transcender os limites dos debates anteriormente travados sobre ela. Trabalhos que são inspirados de um modo ou de outro em Capitalismo é escravidão - como os de Peter Linebaugh e Marcus Rediker, sobre a formação de um proletário atlântico, multiétnico e multicultural; de Andrew O'Shaughnessy, sobre a cisão entre as colônias continentais e as colônias insulares na crise imperial de 1776; de Ian Baucom, sobre o papel da especulação financeira, ligada ao tráfico transatlântico e à escravidão colonial, na formação cultural do capitalismo mundial - demonstram a vitalidade do livro. ${ }^{27}$ Em um registro mais próximo à letra da obra de Williams, Joseph Inikori desenvolveu a ideia a respeito do peso 
decisivo dos africanos escravizados no espaço atlântico para o desenvolvimento industrial inglês; Christopher Brown, a interpretação sobre a centralidade da Revolução Americana para a crise da escravidão britânica; David Beck Ryden, a ideia sobre as motivações econômicas e políticas na abolição do tráfico em 1807; Gelien Matthews, a observação sobre a importância das revoltas escravas de 1816,1823 e 1831 para a campanha antiescravista na metrópole. ${ }^{28}$ Por fim, vale destacar como dois dos mais inovadores trabalhos recentes sobre a escravidão nas Américas, que recorrem a uma perspectiva verdadeiramente integrada e hemisférica com o propósito de elaborar modelos analíticos capazes de dar conta da historicidade, na longa duração, das relações entre capitalismo e escravidão - o de Robin Blackburn, sobre as três idades do escravismo do Novo Mundo, e o de Dale Tomich, sobre a "segunda escravidão" oitocentista - , partiram de um diálogo direto e próximo com Eric Williams. ${ }^{29}$

"Os clássicos são livros que, quanto mais pensamos conhecer por ouvir dizer, quando são lidos de fato mais se revelam novos, inesperados, inéditos": ${ }^{30}$ a avaliação de Ítalo Calvino se ajusta à perfeição ao volume de Eric Williams. A atualidade do livro decorre em grande parte da qualidade das questões que ele apresentou, muito pertinentes a um mundo marcado pelo crescente avanço da degradação do trabalho e da natureza, e da financeirização do capital. Capitalismo \& escravidão, não obstante estar datado em certos aspectos, permanece como uma obra capaz de suscitar novas e surpreendentes leituras - e, assim, de nos ajudar a melhor compreendermos o nosso passado escravista.

\section{Notas}

l Para os elementos biográficos de Eric Williams, ver, além de sua autobiografia Inward Hunger. The Education of a Prime Minister (London: Andre Deutsch, 1972), o livro de Ivar Oxaal, Black Intellectuals Come to Power. The Rise of Creole Nationalism in Trininad and Tobago (Cambridge, MA: Schenkman Publ. Co, 1968, p.56 passim), e o livro mais recente de Colin A. Palmer, Eric Williams of the Making of the Modern Caribbean (Chapel Hill: The University of North Carolina Press, 2006).

2 Coupland teve papel de destaque na Comissão Peel sobre a Palestina (19361937) e nas negociações com os líderes nacionalistas indianos, entre 1940 e 1947. Sobre a escola imperial britânica, veja-se com proveito a introdução de W. Roger Louis ao volume sobre historiografia da coleção The Oxford History of the British Empire (Oxford: Oxford University Press, 1999, v.5, p.1-42).

3 Cf. R. Coupland, The British Anti-Slavery Movement. (1.ed: 1933). London: Frank Cass, 1964.

4 Howard Temperley, Eric Williams and Abolition: the Birth of a New Orthodoxy. In: Barbara Solow; Stanley Engerman (Ed.) British Capitalism and Caribbean Slavery. The Legacy of Eric Williams (Cambridge: Cambridge University Press, 1987, p.229-57), e William Darity Jr., Eric Williams and Slavery: A West Indian Viewpoint? In: Callaloo, v.20, n.4; Eric Williams and the Postcolonial Caribbean: A Special Issue (Autumn 1997, p.800-16) examinam as diferenças entre a tese de doutorado de 1938 e o livro de 1944. Atualmente, Darity Jr. prepara, com Dale Tomich, uma edição integral da tese, que será em breve publicada pelo Fernand Braudel Center da Universidade de Binghamton. 
$5 \mathrm{O}$ ambiente de Howard é bem descrito por Darity Jr, "Eric Williams and Slavery", p.807-12.

6 Há edição em português: Os jacobinos negros. Toussaint L'Ouverture e a $R e$ volução de São Domingos (1.ed.: 1938; trad. Afonso Teixeira Filho. São Paulo: Boitempo Editorial, 2000).

7 Oxaal, Black Intellectuals Come to Power, p.75-6. A mesma passagem é citada por Richard B. Sheridan, "Eric Williams and Capitalism and Slavery: a Biographical and Historiographical Essay". In: Barbara Solow; Stanley Engerman (Ed.) British Capitalism and Caribbean Slave$r y$. The Legacy of Eric Williams (Cambridge: Cambridge University Press, 1987, p.326).

8 A escravidão das plantations e o tráfico negreiro transatlântico, articulados ao mercado metropolitano por meio do comércio triangular, tiveram peso decisivo para a acumulação de capitais que levou à eclosão da Revolução Industrial (tese 1), que, ao vingar, exigiu a abolição do monopólio, do tráfico negreiro e da própria escravidão como condições necessárias para sua expansão (tese 2).

9 Cf. Frank Tannenbaum, A Note on the Economic Interpretation of History. Political Science Quarterly, v.61, n.2, p.247-53, jun. 1946. Um bom sumário das resenhas do livro pode ser lido em Sheridan, "Eric Williams and Capitalism and Slavery", p.319-21.

10 A informação a respeito das primeiras tiragens do livro foi retirada na introdução de Colin A. Palmer (p.xviii-xix) à edição de 1994 da The University of North Carolina Press. As palavras de Sidney Mintz, em entrevista publicada em 2006, são bastante significativas a respeito dessa virada: "Houve todas essas resenhas e as pessoas repensaram e remexeram no livro, e por aí vai. Mas, você sabe, há muitos que tocam Bach, mas de uma forma ou de outra o jeito que eles tocam não se parece com Bach. Gostaria que a maior parte das pessoas que ganharam a vida nos dizendo o que estava errado com Eric Williams fosse ao menos tão inteligente como ele era. Se perguntarmos sobre os livros que se originaram de dissertações, este seria certamente um dos maiores do século. Agora também é interessante [...], ele saiu em 1944, pela Universidade da Carolina do Norte; a tiragem inicial foi como um mil exemplares, que levaram 20 anos para serem vendidos. Então, quando os Estudos Afro-Americanos explodiram, trouxeram de volta Williams, e as edições em capa mole venderam algo como 300.000 cópias". Carnegie, Charles V.; Mintz, Sidney W. The Anthropology of Ourselves: An Interview with Sidney W. Mintz. Small Axe, v.19, n.1, p.106-77, p.137-38, March 2006.

11 Em 2011, a Companhia das Letras publicou uma nova edição de Formação do Brasil Contemporâneo, acrescida de uma entrevista com Fernando A. Novais e um posfácio de Bernardo Ricupero.

12 Cf. Alice P. Canabrava, O açúcar nas Antilhas (1697-1755) (1.ed. 1946. São Paulo: IPE/USP, 1981).

13 Ver, respectivamente, Celso Furtado, Formação Econômica do Brasil (1.ed. 1959. São Paulo: Companhia das Letras, 2009), e Florestan Fernandes \& Roger Bastide, Relações raciais entre negro e brancos em São Paulo (São Paulo: Unesco/Anhembi, 1955).

14 Cf. Gerald R. Bosch Jr., Eric Williams and the Moral Rhetoric of Dependency Theory. Callaloo, v.20, n.4, Eric Williams and the Postcolonial Caribbean: A Special Issue (Autumn 1997, p.817-27).

15 Cf. Fernando Henrique Cardoso, Capitalismo e escravidão no Brasil meridional. O negro na sociedade escravocrata do Rio Grande do Sul (1.ed. 1962. Rio de Janeiro: Civilização Brasileira, 2003); Fernando Henrique Cardoso \& Enzo Faletto, Dependencia y Desarollo 
en América Latina (Mexico: Siglo XXI, 1969).

16 Cf. Emília Viotti da Costa, Da senzala à colônia (1.ed. 1966. São Paulo: Brasiliense, 1989); Fernando A. Novais, Portugal e Brasil na crise do Antigo Sistema Colonial (1777-1808) (São Paulo: Hucitec, 1979).

17 Cf. David Brion Davis, The Problem of Slavery in Western Culture (1.ed. 1966. Oxford: Oxford University Press, 1988, p.223-61); Eugene Genovese, $O$ mundo dos senhores de escravos. Dois ensaios de interpretação (1.ed. ingl: 1969; trad. port. Rio de Janeiro: Paz \& Terra, 1979, p.80-101).

18 Cf. Ciro F. S. Cardoso, O modo de produção escravista colonial na América. In: Theo Santiago (Org.) América Colonial (Rio de Janeiro: Pallas, 1975); Jacob Gorender, O escravismo colonial (São Paulo: Ática, 1978); José Roberto do Amaral Lapa (Org.) Modos de produção e realidade brasileira (Petrópolis: Vozes, 1980).

19 Não é sem surpresa que se constata, na biografia de Eric Williams, a obtenção da Ordem do Cruzeiro do Sul em 1972, honraria que lhe foi concedida no período mais brutal do regime militar brasileiro, no exato momento que seu trabalho era referência importante para a historiografia de inspiração marxista que tratava do passado escravista colonial brasileiro. A condecoração, praxe nas relações internacionais brasileiras, foi oferecida ao primeiro-ministro de Trinidad \& Tobago por ocasião de uma longa viagem do chanceler brasileiro, Mario Gibson Barboza, a diversos países da América do Sul. Há explicação para esse aparente descompasso. A política externa do governo Médici - conhecida como "Diplomacia do Interesse Nacional" - afastou-se do alinhamento ideológico imediato dos governos Castelo Branco e Costa e Silva com os Estados Unidos, abrindo-se para novas relações bilaterais e multilaterais com países da América Latina, da África e do mundo árabe. Foi nesse contexto, por exemplo, que se promoveram gestões concretas de aproximação com a África Atlântica, apenas desenhada no governo Jânio, o que preparou o caminho para o imediato reconhecimento da independência de ex-colônias portuguesas no primeiro ano do governo Geisel. Uma política externa pragmática, focada no desenvolvimentismo, que, ademais, nutria vários pontos de contato com o que Williams vinha praticando desde o encaminhamento dado à crise de Chaguaramas em 1961, evento que esteve na base do seu rompimento político e pessoal com C. L. R. James. Ainda que Williams não seja nela nominalmente citado, a autobiografia de Mario Gibson Barboza [Na Diplomacia, o traço todo da vida (Rio de Janeiro: Record, 1992)] é bastante elucidativa a respeito desses assuntos. Sobre Chaguaramas e a política externa de Williams, ver Oxaal, Black Intellectuals, p.117-36, e Palmer, Eric Williams, p.76-137.

20 No artigo "Estrutura e agência na historiografia da escravidão: a obra de Emília Viotti da Costa" (in: A. C. Ferreira; H. G.Bezerra; T. R. de Luca (Org.) O historiador e seu tempo. São Paulo: Editora Unesp, 2008), que examina os dois livros principais dessa notável historiadora [Da senzala à colônia (1966), e Coroas de glória, lágrimas de sangue. $A$ rebelião dos escravos de Demerara em 1823 (1.ed. em inglês: 1994; trad. Anna Olga de Barros Barreto. São Paulo: Companhia das Letras, 1998)], efetuo um rápido balanço crítico dos ganhos $\mathrm{e}$ das perdas obtidos após os anos 1980.

21 Cf. Ciro F. S. Cardoso, A Afro-América: a escravidão no Novo Mundo (São Paulo: Brasiliense, 1982, p.86-90, 956, 108-9); Escravo ou camponês? O protocampesinato negro nas Américas (São Paulo: Brasiliense, 1987, p.14-6). 
22 Ciro F. S. Cardoso (Org.) Escravidão e abolição no Brasil. Novas Perspectivas (Rio de Janeiro: Jorge Zahar Editor, 1988, p.100).

23 A bibliografia desse debate é enorme. Para o primeiro ponto, veja-se com proveito o livro de síntese de Kenneth Morgan, Slavery, Atlantic Trade and the British Economy, 1660-1800 (Cambridge: Cambridge University Press, 2000). Para o segundo ponto, as referências centrais são o livro de Roger Anstey, The Atlantic Slave Trade and British Abolition, 1760-1810 (London: Macmilan, 1975), e os livros de Seymour Drescher, Econocide: British Slavery in the Era of Abolition (Pittsburgh: University of Pittsburgh Press, 1977); Capitalism and Antislavery: British Mobilization in Comparative Perspetive (New York: Oxford University Press, 1986).

24 Essas críticas, formuladas de modo contundente a partir do final da década de 1960 , nunca tiveram uma resposta direta do próprio Williams, haja vista que, naquela altura, sua carreira de historiador era coisa do passado. Sua história geral do Caribe (From Columbus to Castro. The History of the Caribbean, 14921969 (1.ed. 1970. New York: Vintage Books, 1984), não enfrentou a questão, servindo no fim das contas para situar sua posição no quadro político antilhano coevo.

25 Ver, respectivamente, Barbara Solow \& Stanley Engerman (Ed.) British Capitalism and Caribbean Slavery. The Legacy of Eric Williams (Cambridge: Cambridge University Press, 1987) (com artigos de William A. Green, Barbara L. Solow, Joseph E. Inikori, David Richardson, Selwyn H. Carrington, Richard Dunn, Seymor Drescher, David Brion Davis, Howard Temperley, Michael Craton, Gavin Wright, Hilary Mc.D Beckles, Richard R. Sheridan); Thomas Bender (Ed.) The Antislavery Debate. Capitalism and abolitionism as a prob- lem in historical interpretation (Berkeley: University of California Press, 1992) (artigos de Thomas Haskell, David Brion Davis e John Ashworth); Robin Blackburn, A queda do escravismo colonial, 1776-1848 (1.ed. 1998; trad. Maria Beatriz de Medina. Rio de Janeiro: Record, 2002); Ronald Findlay, The 'Triangular Trade' and the Atlantic Economy of the Eighteenth Century: a Simple General-Equilibrium Model (Princeton: Departament of Economics/Princeton University, Essays in International Finance, n.177, March 1990).

26 Novamente, a bibliografia é ampla. Para dois ensaios historiográficos recentes que esposam essa perspectiva, ver Sidney Chalhoub \& Fernando Teixeira da Silva, "Sujeitos no imaginário acadêmico: escravos e trabalhadores na historiografia brasileira desde os anos 1980. Cadernos AEL. v.14, n.26, p.13-45, 2009; e Robert W. Slenes, Brazil. In: Robert L. Paquette; Mark M. Smith (Eds.) $O x$ ford Handbook of Slavery in the Americas (New York: Oxford University Press, 2010, p.111-33).

27 Cf. P. Linebaugh; M. Rediker, A hidra de muitas cabeças. Marinheiros, escravos, plebeus e a história oculta do Atlântico revolucionário (1.ed: 2000; trad. Berilo Vargas. São Paulo: Companhia das Letras, 2008); A. J. O'Shaughnessy, An empire divided. The American Revolution and the British Caribbean (Philadelphia: University of Pennsylvania Press, 2000); I. Baucom, Specters of the Atlantic. Finance Capital, Slavery, and the Philosophy of History (Durham: Duke University Press, 2005).

28 Cf. J. E. Inikori, Africans and the Industrial Revolution in England. A study in international trade and economic development (Cambridge: Cambridge University Press, 2002); Christopher Leslie Brown, Moral capital. Foundations of British Abolitionism 
(Chapel Hill: University of North Carolina Press, 2005); D. B. Ryden, West Indian Slavery and British Abolition, 1783-1807 (Cambridge: Cambridge University Presss, 2009); G. Matthews, Caribbean Slave Revolts and the British Abolitionist Movement (Baton Rouge: Louisiana State University Press, 2006).

29 Cf. Robin Blackburn, The American Crucible. Slavery, emancipation and human rights (London: Verso, 2011); Dale Tomich, Pelo prisma da escravidão. Trabalho, capital e economia mundial (1.ed. 2004; trad. Antonio de Padua Danesi. São Paulo: Edusp, 2011). Em livro recente, escrito em parceria com Márcia Berbel e Tâmis Parron, procurei seguir as sugestões de Blackburn e Tomich ao analisar de forma integrada a política da escravidão no Brasil e em Cuba nos quadros da economia-mundo capitalista. Ver Escravidão e Política. Brasil e Cuba, c.1790-1850 (São Paulo: Hucitec, 2010).

30 I. Calvino, Por que ler os clássicos (São Paulo: Penguin-Companhia das Letras, 2009, p.21).

Rafael de Bivar Marquese é professor do Departamento de História da FFLCH/ USP, pesquisador PQ-2/CNPq.

@ - marquese@usp.br

Este texto foi publicado como prefácio do livro resenhado. 